\title{
Modeling large offshore wind farms under different atmospheric stability regimes with
} the Park wake model

\author{
Peña, Alfredo; Réthoré, Pierre-Elouan; Rathmann, Ole
}

Published in:

Proceedings of the 2013 International Conference on aerodynamics of Offshore Wind Energy Systems and wakes (ICOWES2013)

Publication date:

2013

Link back to DTU Orbit

Citation (APA):

Peña, A., Réthoré, P-E., \& Rathmann, O. (2013). Modeling large offshore wind farms under different atmospheric stability regimes with the Park wake model. In W. Shen (Ed.), Proceedings of the 2013 International Conference on aerodynamics of Offshore Wind Energy Systems and wakes (ICOWES2013) Technical University of Denmark.

\section{General rights}

Copyright and moral rights for the publications made accessible in the public portal are retained by the authors and/or other copyright owners and it is a condition of accessing publications that users recognise and abide by the legal requirements associated with these rights.

- Users may download and print one copy of any publication from the public portal for the purpose of private study or research.

- You may not further distribute the material or use it for any profit-making activity or commercial gain

- You may freely distribute the URL identifying the publication in the public portal 


\title{
Modeling large offshore wind farms under different atmospheric stability regimes with the Park wake model
}

\author{
A. Peña ${ }^{1}$, P.-E. Réthoré ${ }^{1}$, O. Rathmann ${ }^{1}$ \\ ${ }^{1}$ DTU Wind Energy, Ris $\varnothing$ campus, Frederiksborgvej 399, 4000 Roskilde, DK, aldi@dtu.dk
}

\begin{abstract}
Here, we evaluate a modified version of the Park wake model against power data from a west-east row in the middle of the Horns Rev I offshore wind farm. The evaluation is performed on data classified in four different atmospheric stability conditions, for a narrow wind speed range, and a wide range of westerly wind directions observed at the wind farm. Simulations (post-processed to partly account for the wind direction uncertainty) and observations show good agreement for all stability classes, being the simulations using a stability-dependent wake decay coefficient closer to the data for the last turbines and those using the WAsP recommended value closer to the data for the first turbines. It is generally seen that under stable and unstable atmospheric conditions the power deficits are the highest and lowest, respectively, but the wind conditions under both stability regimes are different. The simulations do not approach the limits of the infinite wind farm under any stability condition as winds are not parallel to the row.
\end{abstract}

\section{INTRODUCTION}

In the last years, investigation of the effect of atmospheric stability on the production of wind farms has gained attention, partly because it has been observed, particularly at large offshore wind farms, that under stable and unstable atmospheric conditions, the wind farms under- and over-perform, respectively, when compared to wind farm data under neutral conditions [1]. Most wake models do not account for stability conditions other than neutral and, thus, model underperformance-when compared to wind farm data-is sometimes attributed to the effect of atmospheric stability.

The Park wake model [2] used in the Wind Atlas Analysis and Application Program (WAsP) [3] is based on the model of Jensen [4], which makes use of the wake decay coefficient $k_{w}$ to estimate the wind speed reduction for a given thrust coefficient, downstream distance, turbine diameter, and upstream wind speed. It is recommended in WAsP to use $k_{w}=0.05$ for offshore wind farms (lower than the recommended value onshore of 0.075). This is because $k_{w}$ is related to the entrainment of the wake in the atmosphere (it is in fact the slope of the expansion of the wake) and as such it is a function of the surface roughness $z_{o}$ (the lower the roughness the less 
wake expansion). Frandsen [5] by semi-empirical means suggested $k_{w}=0.5 / \ln \left(h / z_{o}\right)$, where $h$ is the turbine's hub height, which generally translates into lower $k_{w}$ values than the WAsP recommendations ( $k_{w}=0.039$ for a typical wind turbine offshore). Barthelmie and Jensen [6] found that using $k_{w}=0.03$ adjusted well the results of the Park wake model at the Nysted wind farm when compared to data. Interestingly, at Nysted, i.e. in the South Baltic Sea, stable conditions are mostly observed.

Here, we present an analysis of wind farm data carried out at the Horns Rev I offshore wind farm, where we are able to classify wind turbine power data into different atmospheric stability classes. A set of simulations using a modified version of the Park wake model are performed using different $k_{w}$ values correspondent to particular atmospheric stability conditions. The simulations are post-processed in order to partly take into account the wind direction uncertainty and compared to the data. Since Horns Rev I is a rather large wind farm, for the wind directions analyzed we might expect that some cases will approach the limits of an infinite wind farm. Therefore, we also present the results of the Park wake model evaluated to its infinite theoretical limits.

\section{MODIFIED PARK WAKE MODEL}

We implemented the Park wake model described in Katic et al. [2] in a Matlab script to run simulations for a wide variety of wind directions, wind speeds, wind farm layouts, wind turbine specifications, and $k_{w}$ values. We refer to it as "modified" because in WAsP the model has been extended to account for the effect of ground-reflected wakes from upwind turbines and our version takes into account the wakes upwind (directly or sideways) only.

Peña and Rathmann [7] showed that adjusting $k_{w}$ to match the wind speed reductions estimated by a stability dependent infinite wind farm boundary layer model (a totally different model based on the concept of Frandsen [5], which generally gives higher wind speed reductions in stable compared to unstable conditions) resulted in lower $k_{w}$ values under stable compared to unstable conditions. The adjustment was performed evaluating the Park wake model for an infinite wind farm. Similar results were found when evaluating this 'infinite' Park wake (IPW) model assuming,

$$
k_{w}=u_{* \text { free }} / u_{h \text { free }}=\kappa /\left[\ln \left(h / z_{o}\right)-\psi_{m}(h / L)\right],
$$

where $u_{* \text { free }}$ and $u_{h \text { free }}$ are the undisturbed friction velocity and hub-height wind speed, respectively, $\kappa=0.4$ is the von Kármán constant, and $\psi_{m}(h / L)$ is the extension to the logarithmic wind profile to account for stability and depends on the height (in this case the hub-height) and atmospheric stability by means of $L$ (the Obukhov length). The expressions for $\psi_{m}$ can be found in Peña [8]. Expressions for the IPW model are also given in Peña and Rathmann [7]. Since our Matlab implementation only accounts for upwind wakes, we use the expressions for the same type of wakes.

\section{HORNS REV I WIND FARM}

The Horns Rev I wind farm is located in the Danish North Sea at about $17 \mathrm{~km}$ west from the coast (from the wind farm's northwest corner). A layout of the wind farm showing the positions 
of the 80 wind turbines (rows are named from $\mathrm{A}$ to $\mathrm{H}$ and columns from 1 to 10 ) and three meteorological (met) masts is shown in Fig. 1-left. The turbines are Vestas V80 2 MW machines of 80-m rotor diameter and 70-m hub height. Power and thrust-coefficient curves are illustrated in Fig. 1-right.
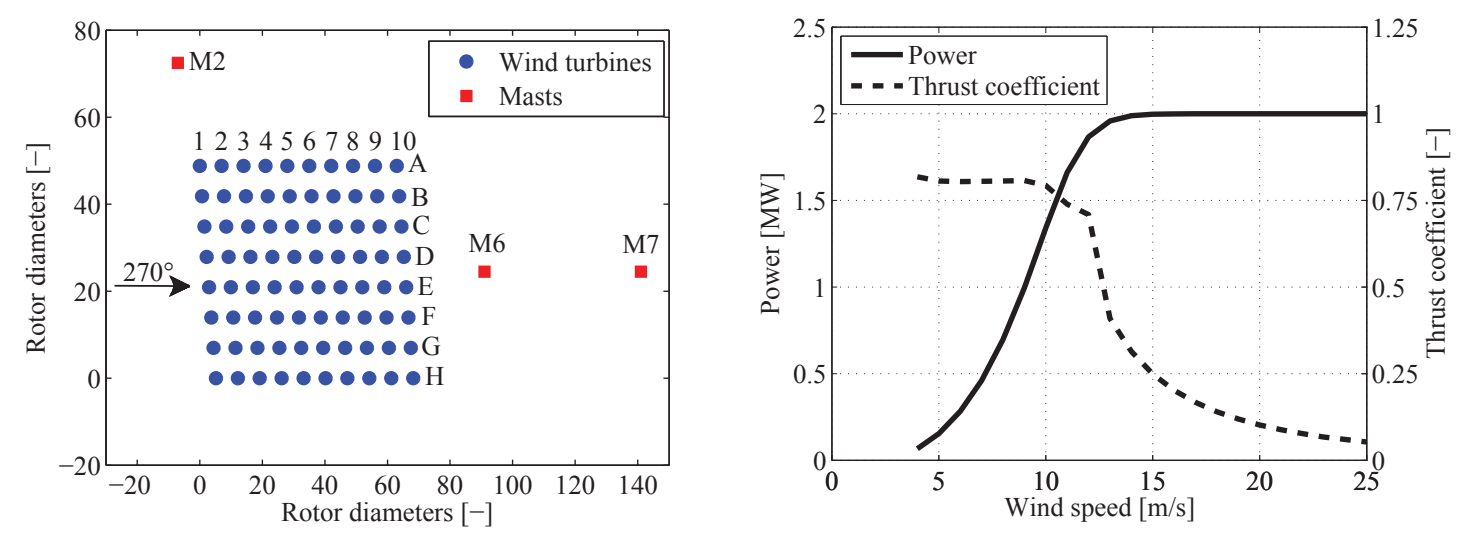

Figure 1: (left) The Horns Rev I offshore wind farm. (right) Power and thrust coefficients as function of wind speed for the Vestas V80 wind turbine (figures taken from [3])

A met mast (M2) is located about $2 \mathrm{~km}$ north from the northwest edge of the wind farm. Met data from this mast have been extensively analyzed for atmospheric stability studies (e.g. in Peña and Gryning [9], Peña et al. [10], and Peña and Hahmann [11]). Here we use measurements from the cup anemometers at 62 and $15 \mathrm{~m}$ above mean sea level (AMSL-all measurements are referred to AMSL hereafter unless otherwise stated), a wind vane at $43 \mathrm{~m}$, temperature sensors at 13 and $-4 \mathrm{~m}$ (the latter is below mean sea level), and humidity and pressure sensors at 13 and $55 \mathrm{~m}$, respectively.

\section{DATA TREATMENT}

Concurrent 10-min data from the wind turbines and M2 are used. Data from the turbines include a power quality signal indicating the status of the turbine and the power signal (stopped, downregulated, etc). We choose to use data when all turbines show status equal to 1 (i.e. a validated measurement where the turbine does not stop and there are no spikes or drop outs).

Atmospheric stability at the wind farm is assessed using the observations at M2. In order to filter data where the climate/conditions are not similar at the two places, we first analyze the wind direction observed at M2 and that at turbine 07 (row G, column 1). For the latter we use the nacelle position, which was found to be optimal for analyzing the wake effect for wind directions $270 \pm 60^{\circ}$ [12]. Figure 2 shows a scatter plot between the two measurements where it is observed a very good correspondence for most cases. We select cases where the difference between both signals is lower than $15^{\circ}$ and where the wind direction at turbine 07 is $270 \pm 60^{\circ}$ (the latter criterion also ensures that no wakes affect the stability estimations at M2 and might allow us to study the array in the limits of the infinite wind farm). 


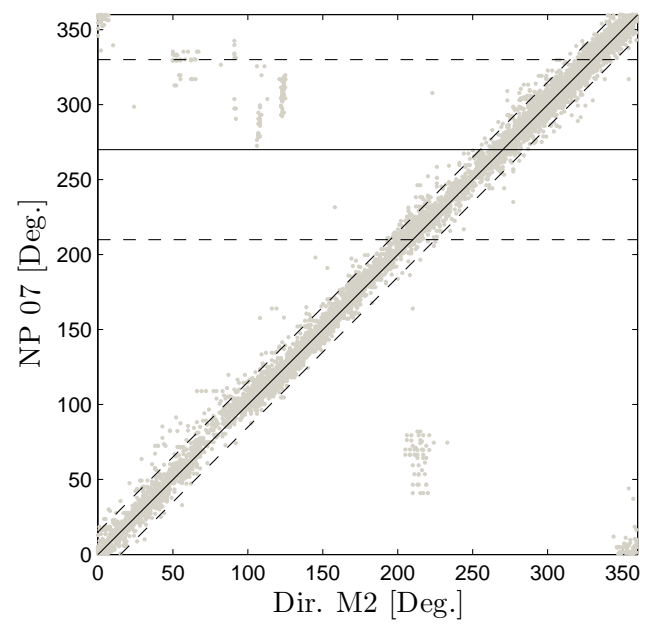

Figure 2: Wind direction observed at M2 at $43 \mathrm{~m}$ and the nacelle position (NP) of turbine 07. The lines illustrate the filtering criteria used for the data (see text)

We further study the agreement between the wind speeds observed at M2 at $62 \mathrm{~m}$ and the nacelle one at M7 at $70 \mathrm{~m}$ (Fig. 3-left). As illustrated both signals show very good agreement and so we use them to further filter data: we choose the wind speed range $5-10 \mathrm{~m} \mathrm{~s}^{-1}$ (since the thrust coefficient is nearly constant within this range) and the difference between both signals needs to be lower than $1 \mathrm{~m} \mathrm{~s}^{-1}$. Before this 'filtering' step, we check the power performance using the wind speed and power signals of turbine 07, which as seen in Fig. 3 compares well with the one provided by the manufacturer (slightly over and under-estimating the power below and above $\sim 10 \mathrm{~m} \mathrm{~s}^{-1}$, respectively).

Our analysis is focused on the wind speed deficits of row E and so we extract power data correspondent to the turbines on that row only. We use another filtering criterion based on the standard deviation of the power signal. It is noted a good amount of data with negative power values and we were advised to use values higher than $5 \mathrm{~kW}$ for the standard deviation of the power for the analysis (Kurt Hansen, personal communication). We increase the criterion to $12 \mathrm{~kW}$. These final reduced dataset is then complemented with the concurrent measurements from M2 (atmospheric static stability is derived as in Peña and Hahmann [11], i.e. estimating the bulk Richardson number, which translates into a measure of $L$ ), and the nacelle position and wind speed of turbine 05 (row E, column 1). Figure 4-left shows the power performance of turbine 05 where a very similar behavior to that observed for turbine 07 is found (Fig. 3-left). For the rest of the analysis, we use the wind speed resulting from converting the power to wind speed of turbine 05 (through the power curve in Fig. 1-right) as a proxy for the undisturbed wind speed. For completeness, we illustrate in Fig. 4-right that the nacelle position of turbine 05 cannot be used for wake analysis since it is rather different to that of turbine 07 . 

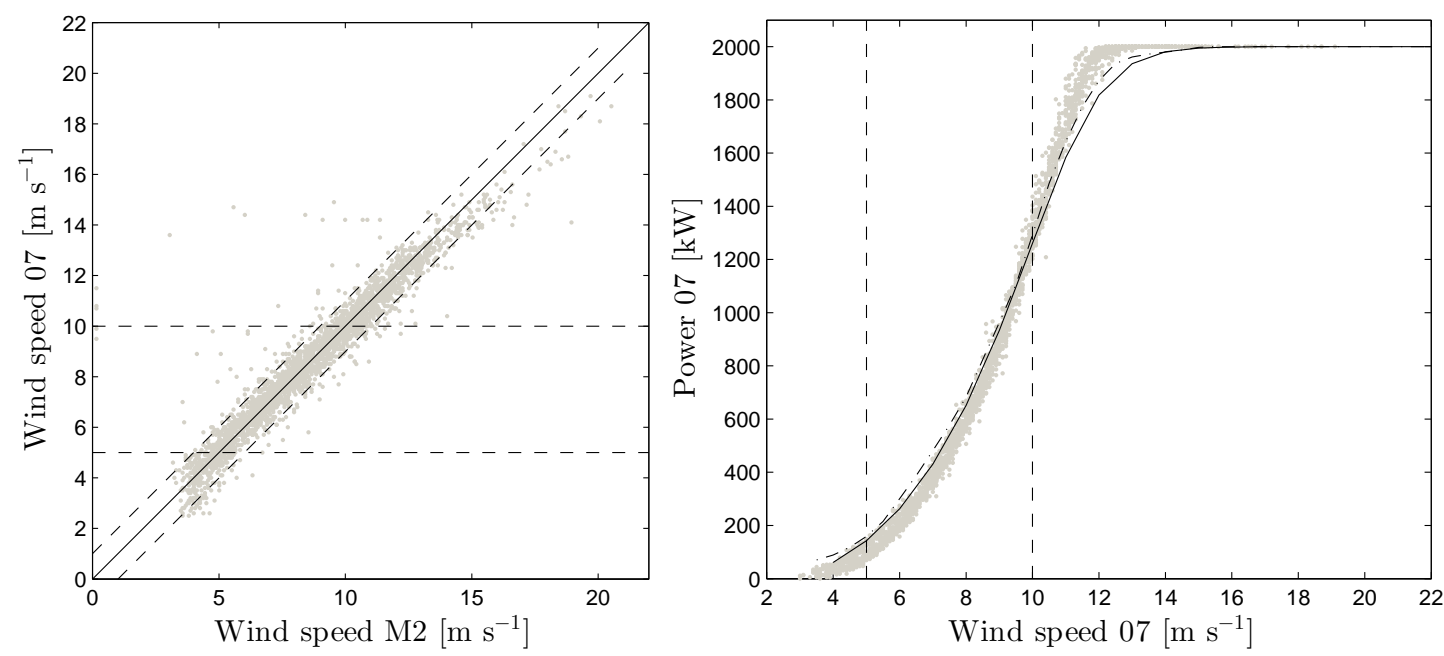

Figure 3: (left) Wind speeds at M2 at $62 \mathrm{~m}$ and that at the nacelle of turbine 07 at $70 \mathrm{~m}$. The lines illustrate the filtering criteria used for the data (see text). (right) Power performance at turbine 07 based on its nacelle wind speed. The lines show two power curves: the one used in this study (solid line) and that from the offshore Vestas V80 wind generator in WAsP (dash-dotted line)

\section{RESULTS}

The final dataset results in 152510 -min values. The data is classified in four stability classes: very unstable $(-75 \mathrm{~m} \leq L \leq-10 \mathrm{~m})$, unstable $(-500 \mathrm{~m} \leq L \leq-75 \mathrm{~m})$, neutral $(|L| \geq 500 \mathrm{~m})$, and stable $(500 \mathrm{~m} \geq L \geq 5 \mathrm{~m})$. Figure 5-left shows the ensemble average of power deficits of row $\mathrm{E}$ (normalized with the power of turbine 05 ) for the different stability classes. Although it is observed a general higher power reduction in stable compared to unstable conditions, this type of comparison is misleading, since the wind speed and direction conditions under each stability class are not the same. Figure-5-right illustrates the histograms of wind speed for the different stability conditions and is noticed that they show different distributions. We further narrow the analysis to wind speeds of $8.5 \pm 0.5 \mathrm{~m} \mathrm{~s}^{-1}$ to reduce the variability of wind conditions maximizing the amount of data.

Although the reduction in the variability of power deficits, for each stability class the difference in the individual 10-min power deficit values is very large. One of the main reasons for this is that the observed wind direction range is rather broad and the distributions are different (Fig. 6). However we cannot narrow the range any further as we might find very few or no data: e.g. most very unstable and unstable conditions are seen within the range $290^{\circ}-310^{\circ}$, whereas there are no data and nearly nothing for that range under neutral and stable conditions, respectively.

For each stability class we choose to run simulations using the Horns Rev I layout (thrust coefficient and power curves as in Fig.1) using the modified Park wake model for $u_{\text {hfree }}=$ $8.5 \mathrm{~m} \mathrm{~s}^{-1}$ and a wide undisturbed wind direction range of $180^{\circ}-360^{\circ}$ (at a resolution of $0.5^{\circ}$ ). This is performed for $k_{w}$ values of $0.05,0.0349,0.0338,0.0313$, and 0.0231 , which correspond, 

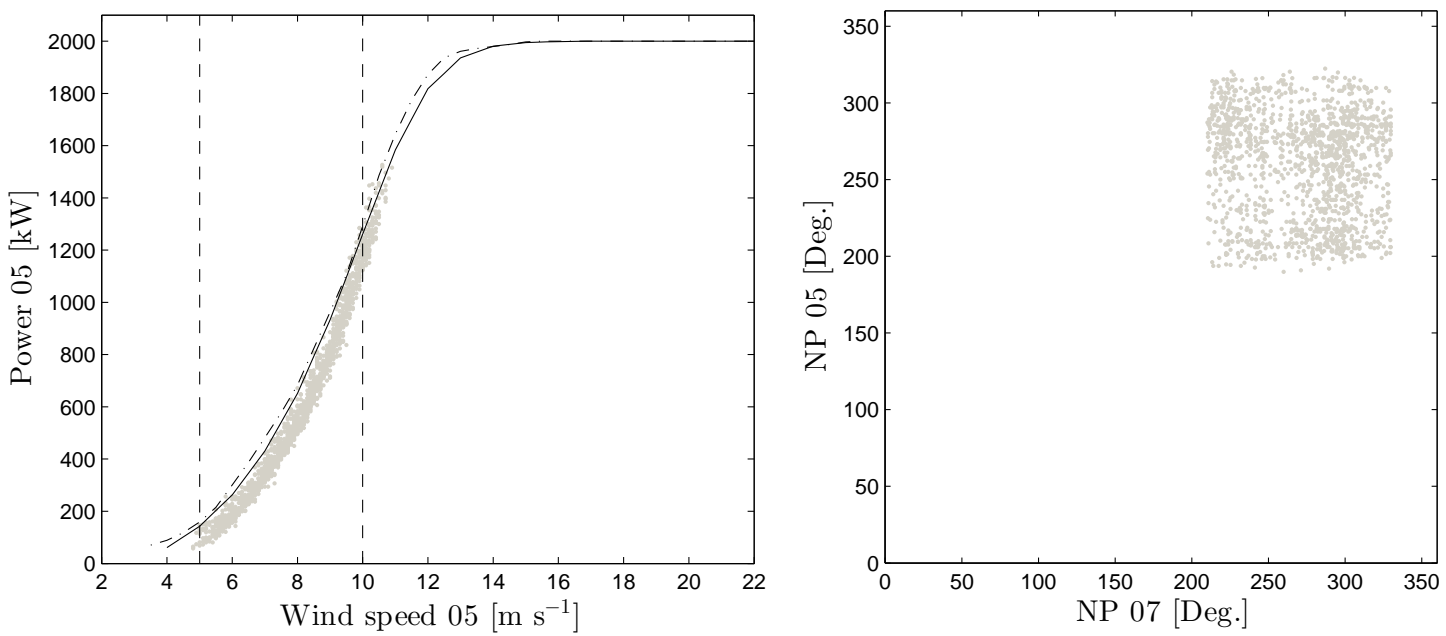

Figure 4: (left) As Fig. 3-right but for turbine 05. (right) Comparison of the nacelle position signals of turbines 05 and 07

respectively, to the WAsP recommended one, and those for very unstable, unstable, neutral, and stable conditions. For the estimation of these coefficients, we average the bulk Richardson number under each class, convert this average into a $L$ value, estimate the $\psi_{m}$ correction at hub height, and evaluate Eq. (1) assuming $z_{o}=0.0002 \mathrm{~m}$.

The simulations are further post-processed to take into account part of the wind direction uncertainty as in Gaumond et al. [13], i.e. assuming that within a 10-min interval the wind direction distributes as a normal distribution with a given standard deviation $\sigma$ (we use a value of $2.5^{\circ}$ ). The procedure is briefly as follows: for each observed 10-min wind direction $\theta$ under each atmospheric stability class, we extract the simulations correspondent to the range $[\theta-$ $3 \sigma, \theta+3 \sigma]$. We then weight each simulation using the normal probability distribution function. For each observed 10-min wind direction and speed deficit, there is therefore a single simulated wind speed deficit (derived from 31 gaussian-weighted simulations).

Figures 7-10 show the results of the comparison of the observed 10-min power deficits and those simulated at row 5 for the different stability classes. They are not shown in the same figure as they correspond to observations/simulations under different wind direction conditions. The ensemble average of both simulations (with a stability-specific $k_{w}$ value) and observations are also shown together with that of the simulations using $k_{w}=0.05$. As the results of the simulations are wind speed deficits, we translate them into power deficits with the power curve in Fig. 1.

The results generally show a very good agreement between the ensemble averages of simulations and observations. For each stability condition the result using the stability-specific $k_{w}$ value shows higher power reductions compared to that using $k_{w}=0.05$, as a lower $k_{w}$ value increases the wake effect. Particularly, under neutral stability conditions, the ensemble average of the simulations using both the stability-specific and WAsP recommended $k_{w}$ values shows that the model predict higher power deficits than observed for all turbines in the row. This is very 

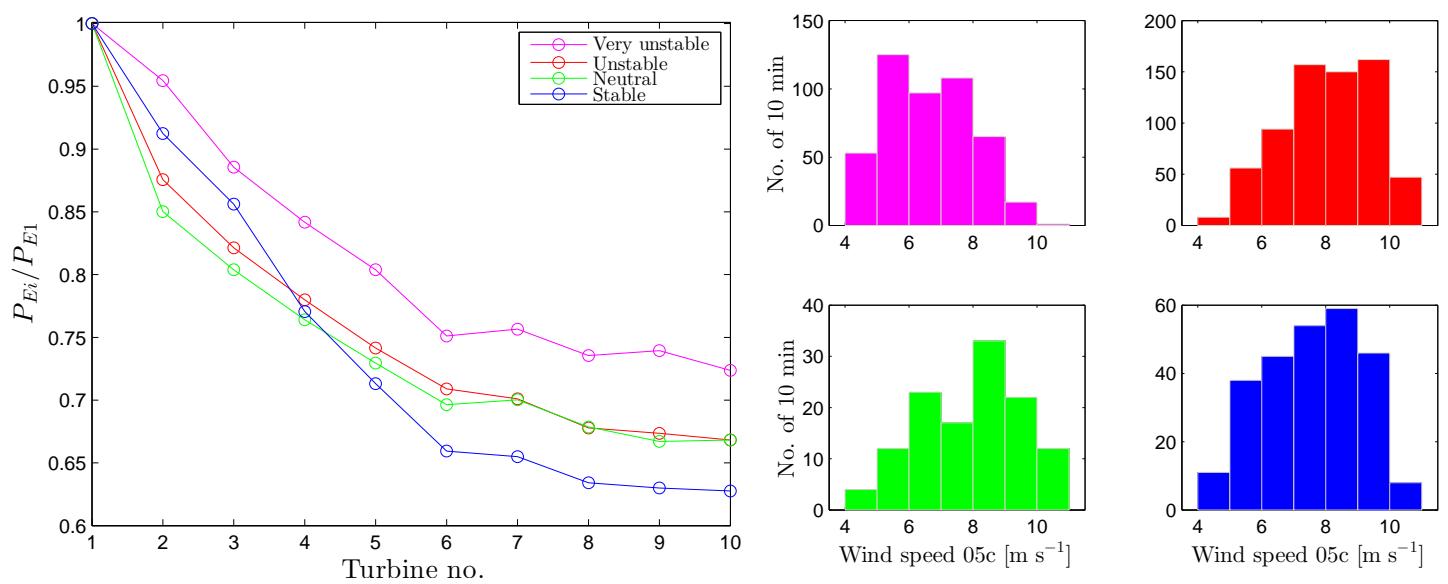

Figure 5: (left) Ensemble average power deficit of row E (normalized with the power of turbine $\left.05 P_{E 1}\right)$ for different atmospheric stability conditions. (right) Wind speed histograms (based on the power-converted value from turbine 05 ) for each stability condition

interesting because in most of the studies at Horns Rev I and at other large offshore wind farms where the Park wake model has been used, the results are normally the opposite: model underprediction of the power deficits. This might be partly due to range of wind directions we use for our analysis and to the post-processing of the simulations accounting for the wind direction uncertainty.

Apart from the neutral case (which is the one with the less data), the simulation with the stability-dependent $k_{w}$ fits better the power deficit at the last turbines in the row compared to the simulations using $k_{w}=0.05$, which in turn generally fit well the results of the first turbines in the row. However, most of the outliers (i.e. the individual 10-min power deficits where $P_{E i} / P_{E 1}>1$ ) are found at those first turbines in the row (there are fewer outliers at the last turbines). Removing such 'outliers' brings the ensemble average closer to the simulation but there is no good reason to remove them as they seem to be good observed data.

We can also note that the range of the results of the simulations and that of the observations for each stability class is well predicted (except for the clear outliers). The cloud of observations (and simulations) of power deficits for unstable conditions is clearly between 0.5 and 0.8 and for very unstable conditions between 0.6 and 0.8 .

The largest power deficit drop is observed at turbine E2 (as expected) and appears in the neutral class (this is the one where most of the observed wind comes from $270^{\circ}$ ). The infinite limits of power reduction are $0.26,0.15,0.28,0.30$, and 0.44 for neutral, stable, unstable, very unstable, and the WAsP-recommended $k_{w}$-values, respectively; none of the ensemble observed power deficits seem to approach the infinite limits.

Also interestingly, under very unstable atmospheric conditions the ensemble average of power deficit (simulated and observed) at turbine E2 is very similar to that at turbine E1; as shown in Fig. 6 for this atmospheric stability condition, there are no observation of winds parallel to the row and winds mostly come from $300^{\circ}$. Turbine E2 is thus mostly affected by partial wakes from turbines E1 and D1. 

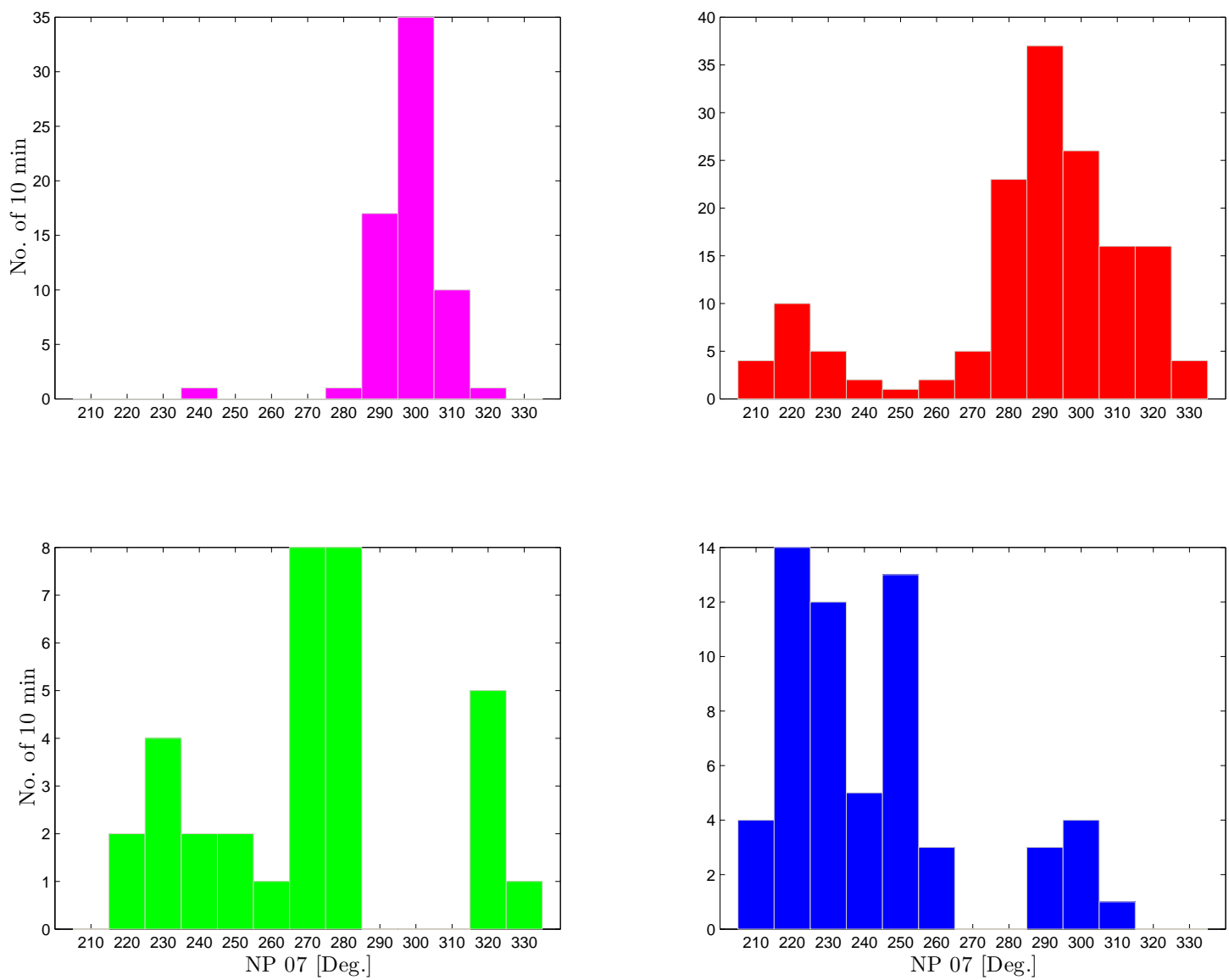

Figure 6: Wind direction histograms (based on the nacelle position of turbine 07) for each stability condition: very unstable (top left), unstable (top right), neutral (bottom left), and stable (bottom right)

\section{CONCLUSIONS}

Power deficit data from the Horns Rev I offshore wind farm are analyzed under different atmospheric stability conditions, a nearly constant undisturbed wind speed, and a wide range of westerly wind directions. The resulting dataset is compared with simulations using a modified version of the Park wake model and the limits of the Park wake model when evaluated as an infinite wind farm.

It is found a very good agreement between simulations and observations for a west-east row in the middle of the wind farm. The simulations using a stability-dependent $k_{w}$ value are closer to the observations at the last turbines and those using the WAsP recommended $k_{w}$ value of 0.05 closer to the observations at the first turbines on that row.

Due to the range of observed and simulated wind directions, it is difficult to conclude whether under stable or unstable atmospheric conditions the wind farm, respectively, under- 


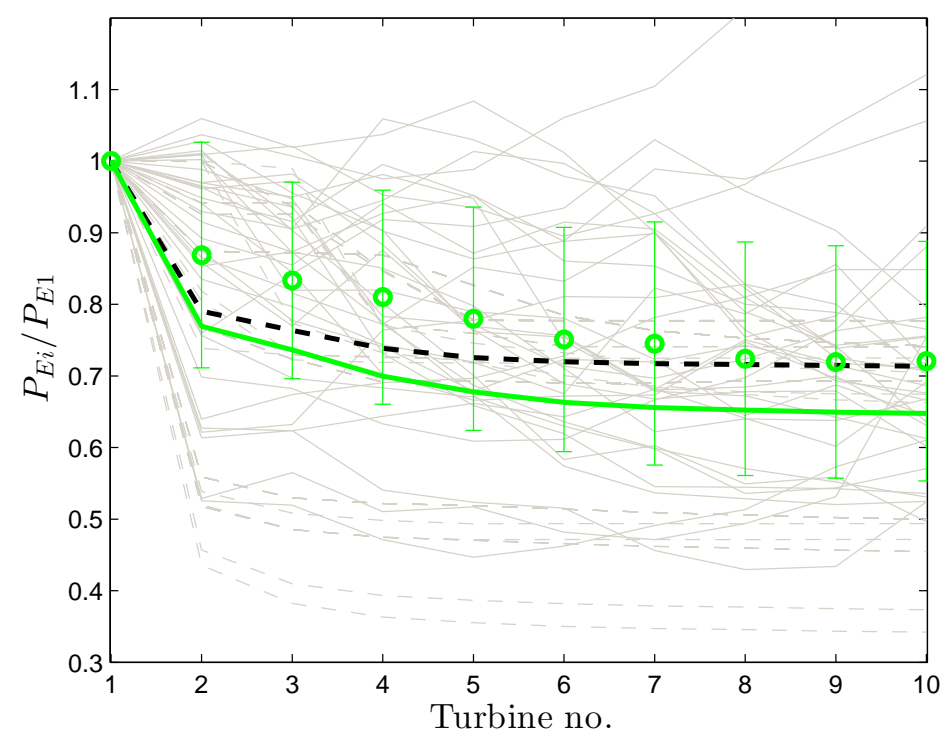

Figure 7: Power deficits of row E (normalized with the power of turbine $05 P_{E 1}$ ) for neutral conditions. The gray solid lines show the 10-min power deficits (in gray dashed lines for each simulation), the colored circles the ensemble average (error bars with \pm the standard deviation), the solid colored line the ensemble average of the simulations with the stability-specific $k_{w}$ value, and the black dashed line that of the simulations with $k_{w}=0.05$

or over-performs. However, it is seen higher power reductions under stable than unstable atmospheric conditions. In none of the conditions, the observations seem to approach the limits of the infinite wind farm.

\section{REFERENCES}

[1] Jensen LE. Array efficiency at Horns Rev and the effect of atmospheric stability. Proceedings of the European Wind Energy Association Conference \& Exhibition, Milano, 2007.

[2] Katic I, Højstrup J, Jensen NO. A simple model for cluster efficiency. Proceedings of the European Wind Energy Association Conference \& Exhibition, Rome, 1986.

[3] Mortensen NG, Heathfield DN, Myllerup L, Landberg L, Rathmann O. Getting started with WAsP 9. Technical Report Ris $\phi-I-2571(E N)$, Risø National Laboratory, Roskilde 2007.

[4] Jensen NO. A note on wind generator interaction. Technical Report Risoe-M-2411(EN), Risø National Laboratory, Roskilde 1983.

[5] Frandsen S. On the wind speed reduction in the center of large clusters of wind turbines. $J$. Wind Eng. Ind. Aerodyn. 1992; 39:251-265. 


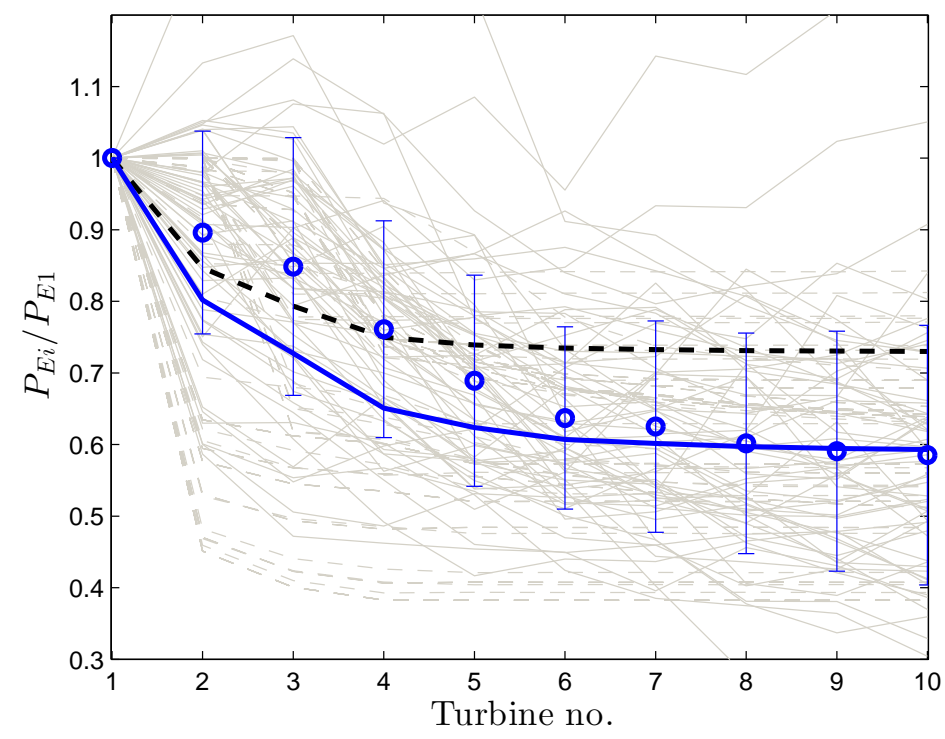

Figure 8: As Fig. 7 but for stable conditions

[6] Barthelmie R, Jensen LE. Evaluation of wind farm efficiency and wind turbine wakes at the Nysted offshore wind farm. Wind Energy 2010; 13:573-586.

[7] Peña A, Rathmann O. Atmospheric stability dependent infinite wind farm models and the wake decay coefficient. Wind Energy 2013; In press.

[8] Peña A. Sensing the wind profile. Technical Report Ris $\emptyset-P h D-45(E N)$, Ris $\emptyset$ DTU, Roskilde 2009.

[9] Peña A, Gryning SE. Charnock's roughness length model and non-dimensional wind profiles over the sea. Bound.-Layer Meteorol. 2008; 128:191-203.

[10] Peña A, Gryning SE, Hasager CB. Measurements and modelling of the wind speed profile in the marine atmospheric boundary layer. Bound.-Layer Meteorol. 2008; 129:479-495.

[11] Peña A, Hahmann AN. Atmospheric stability and turbulent fluxes at Horns Rev-an intercomparison of sonic, bulk and WRF model data. Wind Energy 2012; 15:717-730.

[12] Hansen KS, Barthelmie RJ, Jensen LE, Sommer A. The impact of turbulent intensity and atmospheric stability on power deficits due to wind turbine wakes at horns rev wind farm. Wind Energy 2012; 15:183-196.

[13] Gaumond M, Rethoré PE, Ott S, Peña A, Bechmann A, Hansen KS. Evaluation of the wind direction uncertainty and its impact on wake modelling at the horns rev offshore wind farm. Wind Energy 2013; In press. 


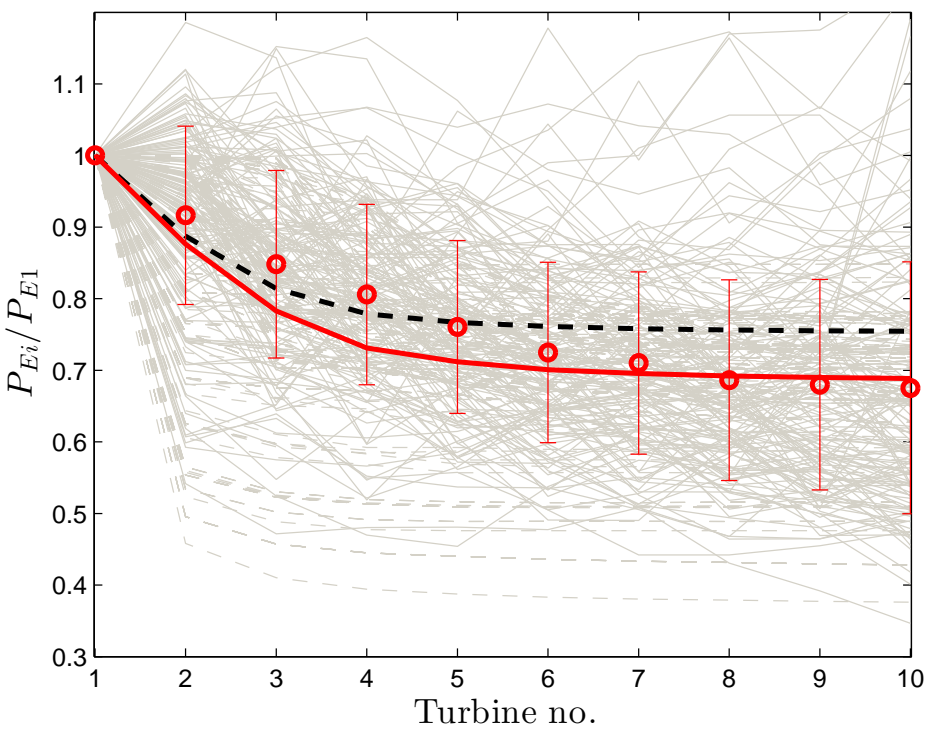

Figure 9: As Fig. 7 but for unstable conditions

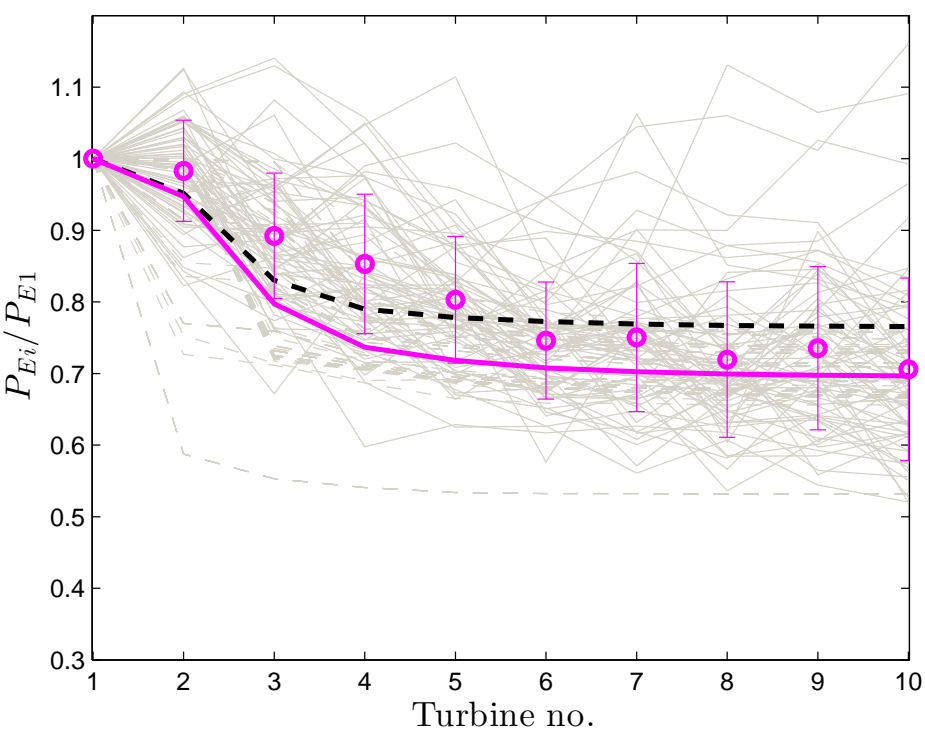

Figure 10: As Fig. 7 but for very unstable conditions 